\title{
A Decision Support System for the Design and Evaluation of Durable Wastewater Solutions
}

\author{
Ramnath Zinjurke \\ Computer Engineering Department, Zeal College of Engineering and Research, Pune, Maharashtra, India
}

\begin{abstract}
To develop the waste water solutions challenging task. To design sustainable wastewater solution requires information about new ideas, new systems and latest technology. Generally it is assumed that, decision making needs to involve field experts and engineers to define values and brainstorms solution. This paper describes a decision support system model that is designed to help community planners to identify the solution which balance the environmental, economic and social needs. System will be scalable, adaptable and flexible. Our decision support system will take modular description of components and description of community constraints, suggest the design of alternative waste water system, and facilitates evaluating how well each design satisfies the given constraints. Decision support system will give alternatives with visualization of the effect of various tradeoffs and their effect in the relation of the community's goals.
\end{abstract}

Keywords: Waste Water Management, Constraint-based processing, decision support, design, environment, Latest technology.

\section{Introduction}

It is notable that, after industrial revolution, population growth and urbanization there is intense need of wastewater management system. As a research, the past few years have been seen significant growth in innovation based on the idea of waste as resource rather than a non-usable material, with a focus on water energy and nutrients. The challenge of providing good management of domestic and industrial sewage is becoming very urgent as the majority of sewage infrastructure in the industrialized area will require changes and replacement in the near future and more than half of the people living in the large cities in the developing world lack access to proper sanitation services. Growing cost in combination with environmental concerns and the challenges involved in securing the quality and quantity of water heighten the urgency of the issue

It has been repeatedly observed that successful implementation of scalable management solutions is strongly tied with environmental ,social, economic and political issues at different level and thus requires active engagement of verity of experts in addition to wastewater engineers identifying the most stable solution involves finding solution that minimize negative effects, while maximizing benefits for local and global environments.

The challenge is considerable, it is context dependent and multidimensional in which competing objectives must be identified and tradeoffs made. Decision makers are struggling to identify the best solution for their specific goal, but they simply do not have sufficient resources to carry out an integrated study, and they generally settled on the general solution [2].

Guest et al. [3] discussed the challenges with sustainable wastewater management and that it is necessary to bring in multiple options when identifying possible solutions. Decision support system (DSSs) can, for example, be designed to allow in boot from different stakeholders involved in the decision making process as planners navigate through complicated problems. Many decision support systems have been created to support take decision in wastewater management [3], [4], [5], [6], [7]; see [8] for a review. Most DSSs focus almost exclusively on the technical and economic aspects wastewater, while what is need is more appropriate approach, which considers social, legal, environmental and other aspects of wastewater management a good decision support system takes input from different users and analyzes the impact of values and other factors.

The motive of this paper is to develop decision support system prototype that we will develop to help communities effectively explore the design space of proper wastewater solutions that is appropriate for their particular context, and make it possible for them to identify solution that balance environmental, economic and social needs. We will allow more provision of new ideas and technologies. We also assume that it would be most beneficial if the DSSs allow users to explore the consequences of various alternatives under different scenario and visualize the tradeoffs between them.

To enable the different components to work together, the DSS should be based on a common vocabulary which can allow the translations of different types of information and concepts between different users of the system. Our decision support system will take input from three types of users.

- Information about physical components by engineers, inventors, technology firms and so on.

- Information of constraints and conditions like geographical, regulatory and demographic given by township planner.

- Information about values, prediction collected from various users like NGOs, elected officials.

Architecture of ours DSS is contains three components. First component is the ontology. The system is built on open platform with other vocabulary of various technical and nontechnical aspects of wastewater solutions. A second 


\section{International Journal of Science and Research (IJSR) \\ ISSN (Online): 2319-7064}

Index Copernicus Value (2013): 6.14 | Impact Factor (2015): 6.391

component is that the system is capable to create alternative solutions. The third component is system is able to effectively communicate the tradeoffs between these alternatives and simultaneously allow users to explore how their values influence the outcome, that is which alternative solutions is best solution and why.

The architecture of our DSS, along with a detailed of our methodology, is presented in the following section.

\section{Literature Review}

Helen E. Moga, James R. Mihelcic [2] had proposed sustainability of waste water treatment technology. The durability of mechanical and the land treatment technologies for wastewater treatment is evaluated, using a set of sustainability indicators developed particularly for this study. The results of this research are an attempt to look beyond the engineering cost and environmental performance related with a particular treatment technology. One of motive of this paper is to start a discussion on how to address more integrated evaluation of the overall sustainability of waste water treatment technology.

J.P. Shim a, Merrill Warkrntin a, James F. Courteney b, Daniel J. Power c, Ramesh Sharda d, Christer Carlsson [9] proposed past, present, future of decision support technology. This is research of past, present and future Decision Support System for waste water management. They have proposed general criteria for implementing Decision Support System for waste water management. Decision Support System researchers, developers and stack holders should

- Check areas where tools are required to transform uncertain and incomplete data, along with qualitative insights, into useful knowledge.

- Give more details about effective decision making by using the intelligent systems and the methods.

- Find advancing software modules to enhance productivity of working and decision making time and

- Give assistance and guidance to DSS users in improving their core knowledge of effective decision support.

V. Novotny [10] proposed Water and Energy Link in the Cities of the Future Achieving Net Zero Carbon and Pollution Emission Footprint. Water and energy uses are intertwined and represent significant portion of the total carbon emission are attributed to water and used water delivery, treatment and disposal. Water conservation is the best alternative solution to water availability problem because it reduces proportionality energy use and carbon emissions. Furthermore, energy can be extracted from used water from heat pump for carbon credit. A common water to water heat pump provides 4-5 times more energy than it uses. The extracted water can be used to warm water in buildings or generate energy. If the water use reduction goals water can be met by water conservation without reuse, a distributed water management system is the best solution whereby highly treated effluent, after heat energy extracted, provide the irrigation, ecological flow to receiving waters and water for down streams uses.
Brent C. Chamberlain, Giuseppe Carenini, Gunilla O berg, David Poole, And Hamed Taheri proposed a decision support system for the design of wastewater solutions. In this system design get generated but there is much scope to improve this system. Instead of generating single design we can generate multiple designs. Revolution of design is possible. Comparing designs will help to choose proper design. Change in design after change in input values will also help to improve designs.

\section{Motivation}

It has been repeatedly shown that successful implementation of robust wastewater management solutions are strongly related to social, environmental, political, economic aspects and political aspects at different scales and thus requires active engagement of variety of experts, in addition to wastewater engineers. Choosing the most sustainable and durable solutions that maximizing benefits of local and global environment while minimize negative effects. Decision makers are struggling to choose the best solution for their specific requirement, but they do not have sufficient resources to perform integrated analysis, and they generally choose traditional solution. The fact that there is real need for decision support system for wastewater management.

\section{Proposed Approach}

A) System Architecture

- The data structure is built on ontology, derived from a number of imported domain specific and domainindependent ontology, which provide an explicit taxonomy and vocabulary for sustainable and durable wastewater management.

- This data structure contains system components, community context and user values and the properties and relationships which of these have with each other

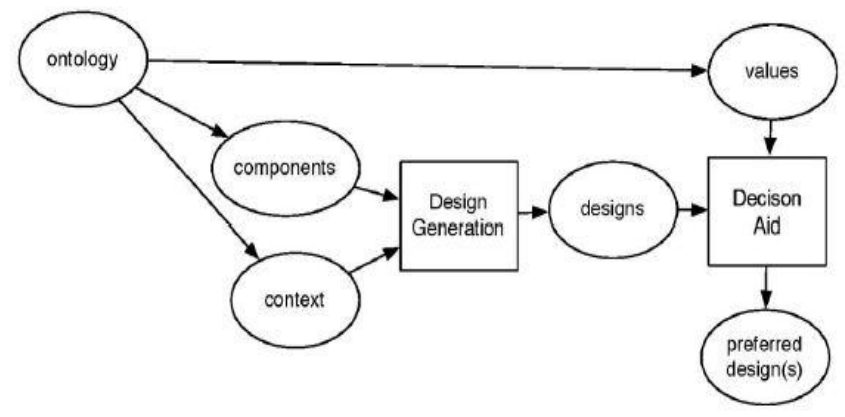

Figure 1: The data structures (ovals) and two software modules (rectangles) of the sustainable wastewater decision support system.

- The design generation module can automatically generate a number of alternative wastewater system designs.

- The decision Aid module support user to choose appropriate design.

System mainly contains following components:

- Creation of ontology: by expert ontology is get created.

- Inputs: Components of wastewater management system, values, relation of components, constrains. 


\section{International Journal of Science and Research (IJSR) \\ ISSN (Online): 2319-7064}

Index Copernicus Value (2013): 6.14 | Impact Factor (2015): 6.391

- Designs creation: generate design using input values, constraint and predefined data in ontology.

- Support to choose design:

○ Compare generated design.

- Evaluate the design.

Change the design after changes in the input values.

B)Algorithm:

Partial design $=$ community

Outputs $=$ community output

Repeat:

Choose output from outputs \&component such that type (outputs) = type (input)

$\&$ all constraints are satisfied

Add component to partial design

Remove output from outputs

If component not in partial design, add outputs of components to outputs

C)Input: Until outputs $=()$

Number of components, values, constraints.

D) Outputs:

Number of waste water management solutions.

E)Method:

- The compatibility of our system searches over combination based on the components which are discovered to be compatible based on the components ontology.

- The idea is, components can be created modularity, so that one components can be described without the need to evaluate how it fits with others.

\section{Conclusion}

In this paper we have proposed a Decision Support System Prototype that, when fully developed, can help community planners to find the design space for sustainable and durable wastewater solution that is relevant for their constraints, and identify wastewater management solution that balance environmental, economic, and social needs. Shift towards sustainable and durable waste water management continues to research, we anticipate that tools like ours can help improve innovation and help communities meet their sustainability goals.

\section{Acknowledgement}

I would like to thank Prof. H.H. Patel for her valuable guidance and motivation. I would like to also thank the researchers as well as publishers for making their resources available and teachers for their guidance. We also thank the college authorities for providing the required infrastructure and support. Finally we would like to extend a heartfelt gratitude to friends and family members.

\section{References}

[1] V. Novotny, "Water and Energy Link in the Cities of the Future-Achieving Net Zero Carbon and Pollution Emissions Footprint," J. Water Science and Technology: A J. Int'l Assoc. Water Pollution Research, vol. 63, no. 1, pp. 184-190, 2011.

[2] J. Foley, D. de Haas, K. Hartley, and P. Lant, "Comprehensive Life Cycle Inventories of Alternative Wastewater Treatment Systems," J. Water Research, vol. 44, no. 5, pp. 1654-1666, 2010.

[3] J.S. Guest, S.J. Skerlos, J.L. Barnard, M.B. Beck, G.T. Daigger, H. Hilger, S.J. Jackson, K. Karvazy, L. Kelly, L. Macpherson, J.R. Mihelcic, A. Pramanik, L. Raskin, M.C.M. Van Loosdrecht, D. Yeh, and N.G. Love, "A New Planning and Design Paradigm to Achieve Sustainable Resource Recovery from Wastewater," J. Environmental Science and Technology, vol. 43, no. 16, pp. 6126-6130, 2009.

[4] T. Loetscher and J. Keller, "A Decision Support System for Selecting Sanitation Systems in Developing Countries," J. Socioeconomic Planning Sciences, vol. 36, no. 4, pp. 267-290, 2002.

[5] N. Dinesh and G.C. Dandy, "A Decision Support System for Municipal Wastewater Reclamation and Reuse," J. Water Science and Technology: Water Supply, vol. 3, no. 3, pp. 1-8, 2003.

[6] D. Joksimovic, J. Kubik, P. Hlavinek, D. Savic, and G. Walters, "Development of an Integrated Simulation Model for Treatment and Distribution of Reclaimed Water," J. Desalination, vol. 188, no. 1, pp. 9-20, 2006.

[7] D. Hidalgo, R. Irusta, L. Martinez, D. Fatta, and A. Papadopoulos, "Development of a Multi-Function Software Decision Support Tool for the Promotion of the Safe Reuse of Treated Urban Wastewater," J. Desalination, vol. 215, no. 1, pp. 90-103, 2007.

[8] M. Hamouda, W. Anderson, and P. Huck, "Decision Support Systems in Water and Wastewater Treatment Process Selection and Design: A Review," J. Water Science and Technology: A J. Int'l Assoc. Water Pollution Research, vol. 60, no. 7, p. 1757, 2009.

[9] J. Shim, M. Warkentin, J.F. Courtney, D.J. Power, R. Sharda, and C. Carlsson, "Past, Present, and Future of Decision Support Technology," J. Decision Support Systems, vol. 33, no. 2, pp. 111- 126, 2002.

[10] M. Maurer, A. Bufardi, E. Tilley, C. Zurbrugg, and B. Truffer, "A Compatibility-Based Procedure Designed to Generate Potential Sanitation System Alternatives," J. Environmental Management, vol. 104, pp. 51-61, 2012.

[11] Brent C. Chamberlain, Giuseppe Carenini, Gunilla O Berg, David Poole and Hamed Taheri, A Decision Support System for Design and Evaluation of Wastewater Solutions, IEEE TRANSACTIONS ON COMPUTERS, VAL.63, NO. 1, JANUARY 2014. 